EXTENDED REPORT

\title{
Colour vision testing as an aid to diagnosis and management of age related maculopathy
}

\author{
G B Arden, J E Wolf
}

See end of article for authors' affiliations

.....................

Correspondence to: G B Arden, Applied Vision Research Centre, Department of Optometry and Visual Science, City University, London ECIV OHB, UK; g.arden@ city.ac.uk

Accepted for publication 1 February 2004
Br J Ophthalmol 2004;88:1180-1185. doi: 10.1136/bjo.2003.033480

Aim: To provide a simple test that detects the onset of age related maculopathy (ARM), and can be used to monitor its severity.

Methods: Colour contrast sensitivity was measured using computer graphics techniques. Colour thresholds were measured along tritan and protan colour confusion axes in the presence of dynamic luminance noise. Thresholds were determined separately for two sizes of optotypes $\left(6.5^{\circ}\right.$ and $\left.1.5^{\circ}\right)$. Natural pupils were used. Normal values for the test have been established.

Results: In all patients with unilateral age related macular degeneration, the smaller optotype was invisible in that eye and in almost all, the larger optotype could not be seen. In the symptomless fellow eyes (with ARM) the larger optotype thresholds were raised. The degree of loss was larger for tritan. For the smaller optotype, protan thresholds were elevated in the majority of patients. Tritan losses were greater and disproportionate to the loss seen with the larger optotype. Every person including those with minimal fundal changes had tritan test results for 1.5 degree optotypes $>2$ SD above the normal mean. Tritan thresholds varied with the severity of the ARM.

Conclusions: The test is sensitive, simple and quick to administer, and easy for patients. Therefore, it should be useful in detecting and monitoring elderly people with age related changes in their fundi before irreversible loss of vision has occurred. litions $\mathrm{t}$ is common for ophthalmologists to see patients with age related maculopathy (ARM) only after considerable uniocular irreversible visual loss has occurred..$^{1-5}$ A screening programme involving simpler tests that could be carried out by non-specialists ${ }^{6}{ }^{10}$ is needed to identify "at risk" patients who have no symptoms. Even if methods of treatment are not very efficacious, the condition is so common that screening would result in very considerable sight saving..$^{11} 12$ Various methods have been proposed. The results from electro-oculograms (EOGs), non-photic EOGs, electroretinograms (ERGs), pattern electroretinograms (PERGs), and multifocal ERGs are controversial. ${ }^{13-23}$ Psychophysically determined losses of rod sensitivity have been reported to occur before other symptoms. ${ }^{24-26}$ Slight losses of visual acuity occur in patients with large soft drusen, and there may be slight and various changes with Amsler chart. ${ }^{27}$ Various losses of cone function have been investigated..$^{1828-29}$ Colour vision testing with the D-15 or 100 hue test has not been found useful. ${ }^{27-29}$ However, it has been reported that blue on yellow perimetry (short wavelength automated perimetry, SWAP) ${ }^{30}$ or colour matching ${ }^{31}$ can detect early changes in ARM. Colour contrast sensitivity testing ${ }^{32-40}$ offers significant advantages in speed and ease of administration, important for screening purposes, ${ }^{36-7} 394142$ and although not widely employed in ARM, ${ }^{41-44}$ small losses occur in otherwise symptomless patients after a period as short as a year. ${ }^{41}$ This paper is the first report on the possibility of screening using (in a small series) a modified method of colour contrast sensitivity testing. Apart from technical modifications to software and hardware, we investigated the effect of using a flashed smaller optotype confined to the central macula. The sensitivity for detecting ARM was thereby improved and the results suggest how screening for ARM might be carried out in larger surveys.

\section{METHODS \\ Equipment}

Colour contrast sensitivity was measured with a revised version of the equipment used in previous work. ${ }^{32-34}$ In this test, isoluminant coloured optotypes are generated on a calibrated monitor, on a white background of $\sim 20 \mathrm{~cd} . \mathrm{m}^{2}$ and the colour difference between the optotypes and a neutral (white) background is altered until the threshold of visibility is obtained. The most important software improvements for the new model were (1) the superimposition of random dynamic luminance noise on the coloured optotype that the patient had to name. ${ }^{45}$ Such noise effectively masks any luminance clues in recognising the optotype (colour contrast sensitivity is unaffected by such luminance masking. ${ }^{40}$ The luminance noise contrast defined as $\left(\mathrm{L}_{\max }-\mathrm{L}_{\min }\right) /\left(\mathrm{L}_{\max }+\right.$ $\mathrm{L}_{\mathbf{m i n}}$ ) was 0.4, greater than any luminance difference between the optotype and the surround. (2) In addition, the psychophysical routines were made more efficient so the test stops automatically when a preset degree of precision has been attained. Between six and 15 observations, at 3-5 second intervals are required to establish a threshold. The protan and tritan colour confusion lines along which the colours were modulated formed the major and minor axes of a MacAdam ellipse centred on white. ${ }^{45}$ We used two differing sizes of optotype, subtending 6.5 and 1.5 degrees, viewed at 1 metre.

\section{Calibrations}

The results of the test are expressed as a percentage of the maximum modulation of colour possible along the chosen colour confusion line.

Abbreviations: $A M D$, age related macular degeneration; ARM, age related maculopathy; EOG, electro-oculogram; ERG, electroretinogram; PERG, pattern electroretinogram 


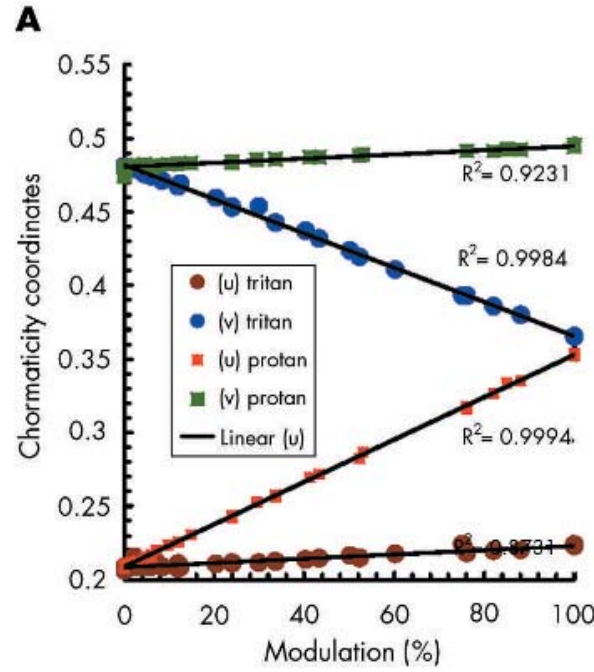

B

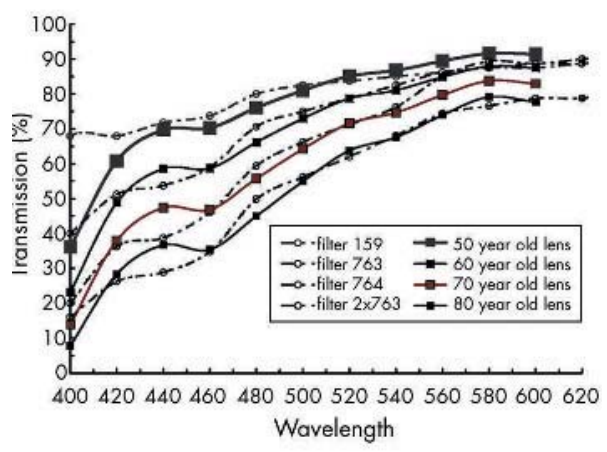

C

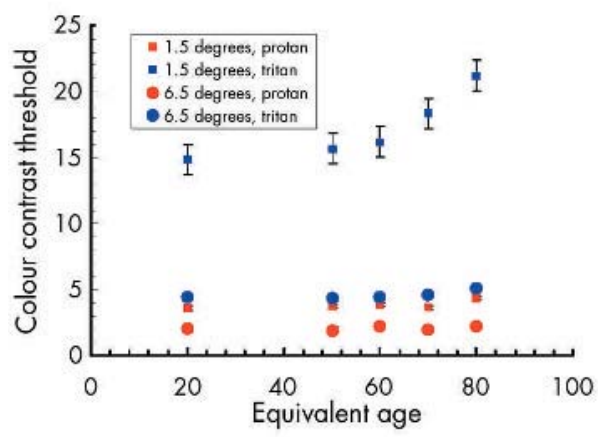

Figure 1 (A) Changes to measured chromaticity with change of modulation depth. (B) Reduction in lens transmission as a function of age $^{46}$ compared to the transmission of filters for ages 50,60,70, and 80. The filters were as follows; plastic filters provided by Lee Filters, Ltd, UK. For 50 year old data No 159, for 60 year old No 763, for 70 year old No 764, for 80 year old two layers of No 763. (C) Changes in thresholds with yellow filters in 20 year old subjects. The vertical bars are plus or minus 1 SD, and are within the symbols except for the smaller tritan optotypes.

Figure 1A shows the relation between measured chromaticity and displayed modulation, and the correlation coefficients for the four sets of measurements (all >0.99). The standard errors of the slopes are between 0.00001 and 0.000055 chromaticity units. A $1 \%$ change in threshold is equal to a displacement in colour space of 0.0012 unit. The change in luminance of the optotypes from 0 to $100 \%$
A

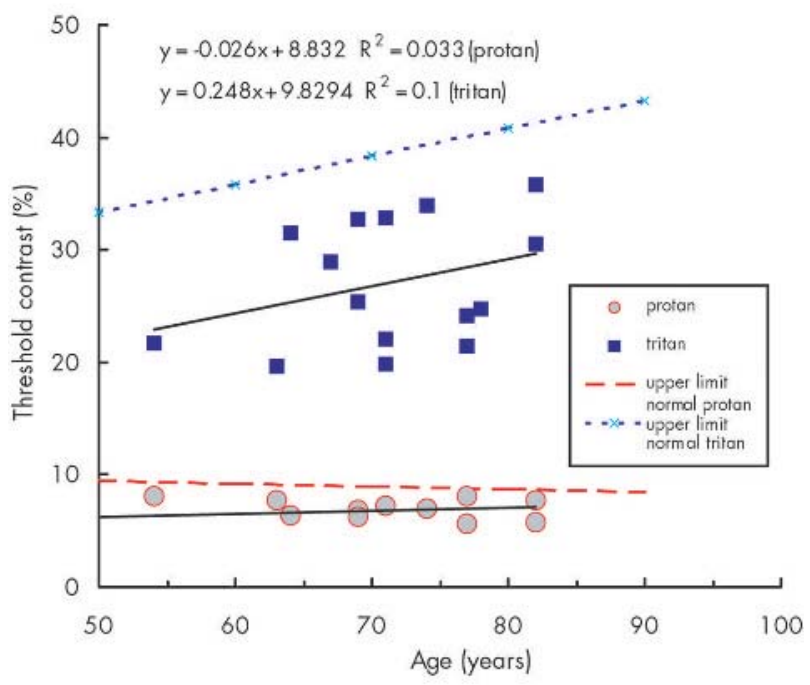

B

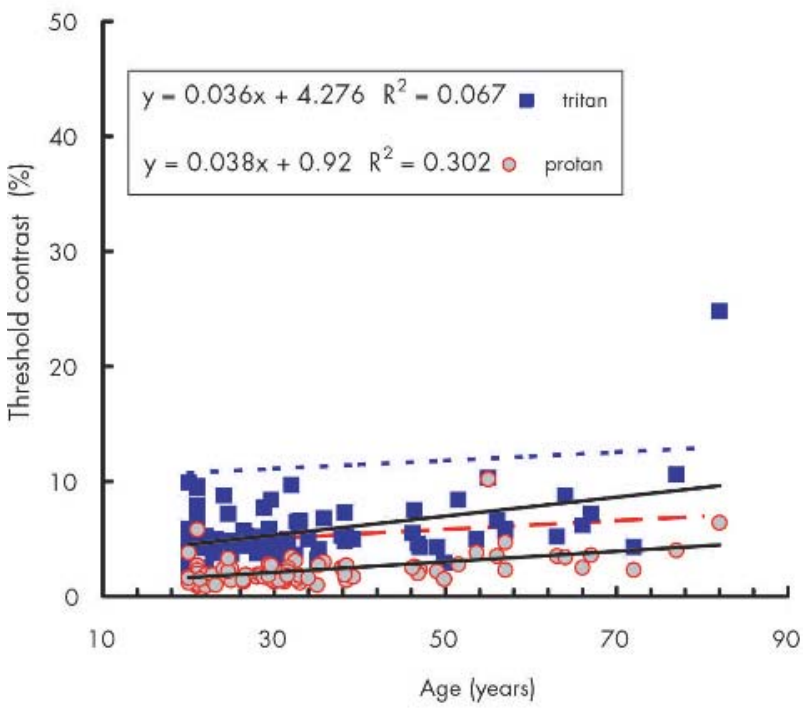

Figure 2 (A) Normal results for smaller optotypes in an older population. The trend line equations are shown. The blue broken line is 2 SDs above the normal mean values for tritan thresholds, and the red broken line is the upper limit of normal for the protan threshold.

(B) Normal results for larger optotypes in an older population. The trend line equation are shown and refer to values obtained in patients with measureable thresholds ( $<100 \%)$. The blue broken line is 2 SDs above the normal mean values for tritan thresholds, and the red broken line is the upper limit of normal for the protan threshold.

modulation was measured as $0.8 \mathrm{~cd} . \mathrm{m}^{2}$ for protan letters and 0 for tritan letters. Variations in the optical density of macular pigmentation, or changes due to lens yellowing that occur with age might also affect thresholds. In eight 20 year old subjects, with $3 \mathrm{~mm}$ artificial pupils, thresholds were determined using a variety of yellow filters that approximated to the changes in lens transmission. ${ }^{46}$ Figures $\mathrm{IB}$ and $\mathrm{C}$ show the filters and the changes in threshold associated with their use. Only with the smaller tritan letters and filters associated with 70 and 80 year old people do thresholds increase slightly, consistent with recent work. ${ }^{47}$ 


\section{Normal values}

\subsection{Degree optotypes}

Sixteen elderly people were recruited, spouses of members of the Macula Disease Society, the authors, their friends, and relations. Three of the people initially recruited as normals proved on examination to have early fundal changes of ARM, abnormal colour vision, and (in two cases) abnormal alcohol responses in the EOG. ${ }^{48}{ }^{49}$ They were excluded. All the rest had no systemic or eye disease that might affect vision, normal fundi, and normal corrected visual acuity. The mean age was 71.75 (range 57-82). The mean visual acuity was 0.93 (range $0.7-1.5$ ). Contrast thresholds were protan: $6.63 \%$ (SD $1.22 \%$ ) and tritan: $26.8 \%$ (5.5\%); seven were female and nine male. Female thresholds were 6.9 (protan) and 28.0 (tritan). Male thresholds were $6.4 \%$ (protan) and $26.0 \%$ (tritan). The 65-74 year old thresholds also differed insignificantly from the 75-84 year old group. For protan, the means were $7.0 \%$ and $6.4 \%$ respectively. For tritan the values were $28.0 \%$ and $27.7 \%$ respectively. These tritan values are very similar to those of young people, tested with yellow filters (fig $1 \mathrm{C}$ ).

Figure 2A shows the results for 1.5 degree optotypes. The regression of threshold on age is insignificant $\left(r^{2}=0.068\right)$. The slope of the relation between age and threshold is 0.864 , with a standard error (SE) of 0.71 , and for protan 0.264 , with an SE of 0.167-that is, not significantly different from zero. The broken lines in the figure represent upper limits of normal, obtained by fitting a least squares linear regression to the data, finding the mean value at each age and adding twice the value of the standard deviation of the entire group. Should there be a regression with age, the actual SD at any age would be smaller than assumed. Alternatively an upper limit of $(26.8+(2 \times 5.5))=37.8$ could be used, but this is a less severe criterion for anyone aged more than 73 .

\subsection{Degree optotypes}

These have been used in the investigation of other conditions, and 96 normals, mean age 34.6 (range 20-81) were available (fig 2B). The mean protan threshold is $2.4 \%$, (SD 1.5) and the mean tritan, $5.7 \%(2.9)$. Forty per cent were female. The mean age of male and female groups was the same, as were the colour thresholds and their regression on age. Disregarding the one tritan outlier in figure $2 \mathrm{~B}$, regression analysis shows a slope of 0.04 threshold units per year, with an SE of 0.01 for both tritan and protan. Thus, there is a small though significant change with age that is the same for both protan and tritan letters, in agreement with data of NguyenTri et al. ${ }^{47}$ For consistency, the upper limits of normal have been defined as for figure 2A. Allowing for the very small effect of age on mean threshold, large protan optotype thresholds are smaller than those of 1.5 degree optotypes by a factor of 1.9 For tritan, the ratio is 3.2, reflecting the relative paucity of blue cones in the central 1.5 degrees.

\section{People with ARM}

Three people who volunteered as elderly normals and were found to have minimal fundal signs of ARM are included in this group. Twenty one other patients with various stages of ARM were recruited from meetings of the Macular Disease Society. The entry criteria were general good health, mobility unimpaired; no systemic hypertension; no diabetes; no other systemic disease; no other ocular disease (except minimal lenticular opacity); one eye may have loss of vision due to AMD; fellow eye must have no symptoms and visual acuity $\geqslant 0.6$. The mean age was 76 . A subset of these patients had been subject of other investigations. ${ }^{49}$ Four of the patients were not tested with 6.5 degree optotypes. All had been investigated in UK eye departments and had been given firm diagnoses of ARM. All were clinically re-examined and a
A

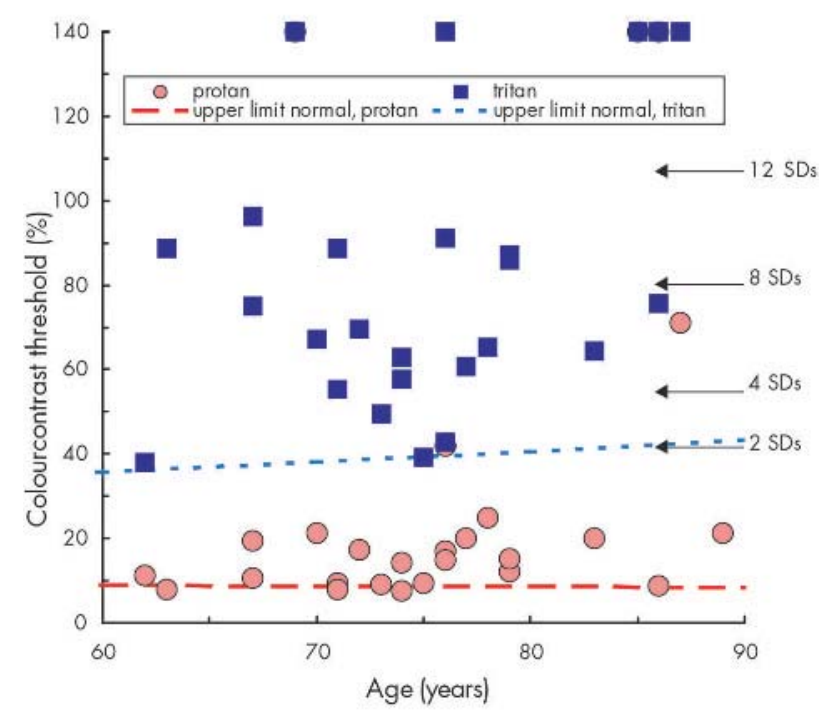

B

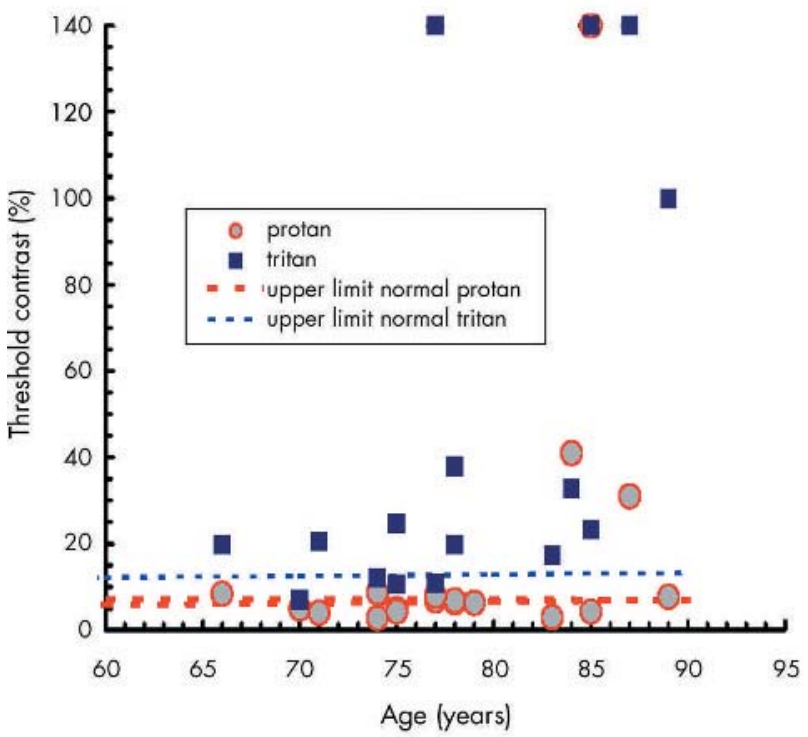

Figure 3 (A) Thresholds for 1.5 degree letters in patients with ARM. The upper limits of normal are transferred from figure 2. Note the difference in vertical scaling. (B) Thresholds for 6.5 degree letters in patients with ARM. The upper limit of normal is transferred from figure 2. Note the difference in vertical scale between this figure and figure 2.

history taken. The three least affected had good vision in either eye. Copies of clinical records were obtained. In some cases, fluorescein angiographic results were available. In a subgroup of 16, reported by us previously, ${ }^{49}$ fundi were photographed. Because of difficulties in some patients with full dilatation of the pupils, and media that were not completely transparent, $25^{\circ}$ stereoscopic views did not give adequate results in all cases. To maintain consistency, we compromised and took $45^{\circ}$ views, enlarging them to $\times 40$, and used the grid and definitions and scoring procedures laid out by Bird $e t ~ a l^{50}$ to grade and rank the severity of the changes within the group studied. ${ }^{49}$ All patients gave informed consent conforming to the second declaration of Helsinki. 


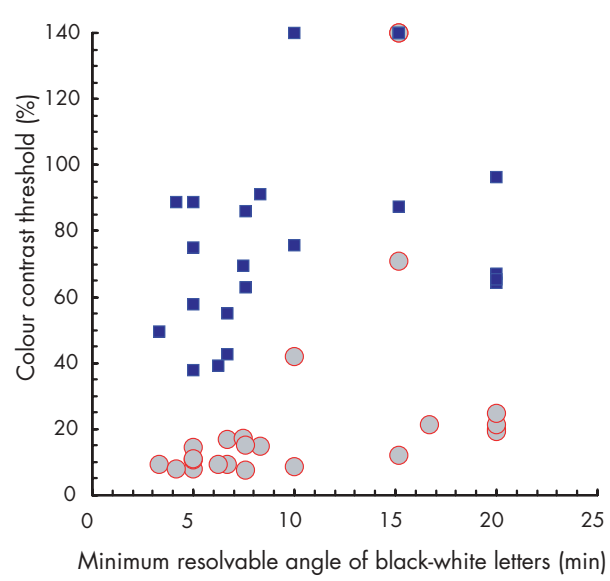

Figure 4 Relation of thresholds to visual acuity. 5' arc indicates an acuity of 1.0, and $50^{\prime}$, and acuity of 0.1 (this method of plotting is designed to present the result more clearly).

\section{RESULTS}

\section{Colour contrast thresholds in patients' worse eyes}

Most of the patients had a considerable degree of loss of visual acuity in one eye. In all such eyes the smaller coloured letters could not be identified at all. The large tritan optotypes were read by only three individuals at $100 \%$ contrast, while four could distinguish protan coloured letters at 100\% contrast. Therefore, the analysis below is confined to the better, fellow eyes.

\section{Better eyes, 1.5 degree optotypes}

Figure $3 \mathrm{~A}$ shows the results for the smaller optotypes. If the optotypes could not be read at all, thresholds are arbitrarily given the value of $140 \%$.

Both the 1.5 degree protan and tritan thresholds increase with age. The slope for protan is 0.26 threshold units/year, with an SE of $0.167, r^{2}=0.12$ while for tritan the values are 0.86 , and $0.71, r^{2}=0.08$. These results are not significant, but no such increase with age was seen in the normal group. The tritan losses are greater than the protan. Thus, 11 of the protan results are abnormal and in three patients the letters could not be identified at all. The 17 tritan thresholds are very high, much above the upper limit of normal and in five the threshold could not be measured. Thirteen of the protan but only seven of the tritan thresholds are less than twice the normal values. The probability of this being the result of chance $\left(\chi^{2}\right)$ is 0.014 . Figure 4 shows the relation of thresholds of 1.5 degree optotypes as a function of the reciprocal of visual acuity. For visual acuity of $<0.7$, there is no obvious relation between colour contrast threshold and acuity.

\section{Better eyes, 6.5 degree optotypes}

Even though the protan results are frequently near normal with large optotypes (fig 3B), the tritan thresholds are clearly elevated. Three "better eyes" could not see any 6.5 degree tritan letters and only one could not see any 6.5 degree protan letters. Two other protan results are considerably higher than the upper limit of normal. The remainder of the protan results cluster about the upper limit of normal. Nine of the tritan thresholds are considerably higher than the upper limit of normal, and only three are below it. Ten of the protan results and four of the tritan are less than twice the normal values. The probability of this being due to chance $\left(\chi^{2}\right)$ is 0.002 .

\section{Interactions}

For large letters, the protan and tritan thresholds are well correlated $(r=0.64)$ but for small, the correlation is much less $(r=0.21)$ The correlation between large and small letters for protan is 0.87 , while for tritan the correlation is poorer $r=0.55$. These results exclude those in whom the optotypes could not be seen. These correlations reflect the selective increase in threshold seen with the smaller tritan optotypes.

\section{Relation to fundus appearance}

In a subgroup of patients fundal appearances were ranked, ${ }^{49}{ }^{50}$ and compared to the colour contrast results, using Spearman's rank order correlation methods. The correlation coefficients are given in table 1 . For $n=14$, the minimum level for a $95 \%$ rejection of the null hypothesis is 0.545 , so only the result with the smaller tritan letters is not significant. This is probably because of the large number of results which are "tied" - that is, have equal rank because no letters could be seen. Again, this reflects the selective increase in threshold with the smaller tritan optotypes. The highest value of the coefficient is given from the results on large tritan letters.

Figure 5 summarises the change in threshold with clinical state. On the left is a nearly normal fundus, with one or two large soft drusen. The larger optotype thresholds are within normal limits. The small optotype tritan threshold is high, but just less than 2 SDs above the mean. The central image shows a fundus with many confluent drusen. The patient's vision was excellent and there were no symptoms. The central retinal region shows up as darker, because of areas of retinal and retinal pigment epithelium thinning showing choroidal coloration. Protan thresholds are normal, but even the larger tritan optotype gives an abnormal result. On the right is the fundus image of a patient who has, additionally, oedema and pigmentation. Visual acuity is reduced, and all colour contrast tests give very abnormal results.

\section{DISCUSSION}

There is an enormous loss of the ability to recognise tritan optotypes in early ARM, unrelated to the yellowing of the lens or to visual acuity but related to the severity of the retinal changes and to age. The distinction from normals is much greater than that found by older methods of assessing colour vision. ${ }^{30}{ }^{31}$ Previous reports on colour contrast sensitivity in $\mathrm{ARM}^{41-4451}$ are consistent with our work which also investigates the findings in patients at various stages. The reason that the present technique appears more successful may be that the optotypes were flashed briefly. Eye movements could not assist the recognition of the letters, so while a coloured region on the screen could be seen, the letter could not be identified. It is possible that there are small perifoveal scotomas for blue in these patients that impede letter discrimination. Whatever the reason, there is an almost

\begin{tabular}{lllll} 
Table 1 & Correlations between colour test and fundus appearances \\
\hline Image & $6.5^{\circ}$ protan & $6.5^{\circ}$ tritan & $1.5^{\circ}$ protan & $1.5^{\circ}$ tritan \\
\hline Spearman correlation* $(n=14)$ & 0.664 & 0.714 & 0.711 & 0.470 \\
\hline *Fundus appearance correlated to colour vision threshold. & &
\end{tabular}




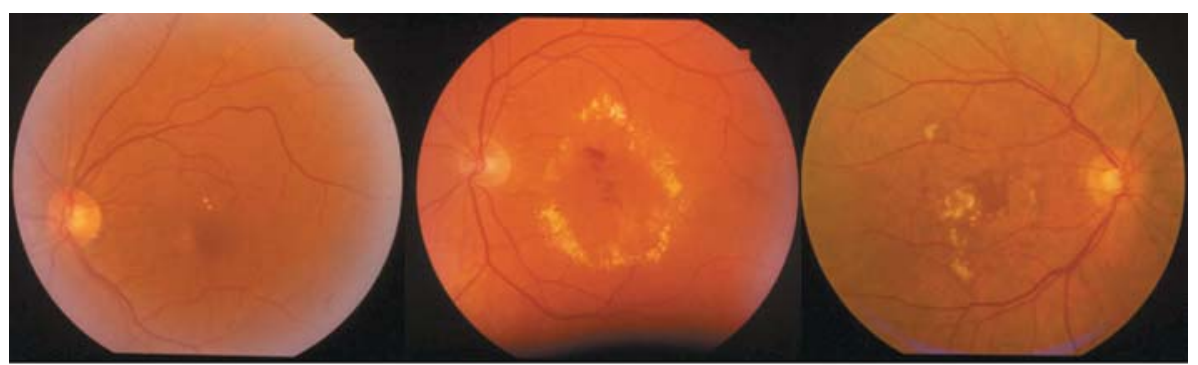

Figure 5 See text.

JW 63 years VA $=1.0$

AW 71 years $\mathrm{VA}=1.0$

DB 69 years VA $=0.3$

Thresholds for Large Letters $\left(6.5^{\circ}\right)$

\begin{tabular}{|c|c|c|c|c|c|}
\hline protan & tritan & protan & tritan & protan & tritan \\
\hline $5.3 \%$ & $9.1 \%$ & $5.7 \%$ & $\underline{19.9} \%$ & $\underline{65.6} \%$ & not seen \\
\hline & & Thresholc & mall Lett & & \\
\hline protan & tritan & protan & tritan & protan & tritan \\
\hline $7.9 \%$ & (32.7\% & $7.9 \%$ & $\underline{88.1} \%$ & not seen & not seen \\
\hline
\end{tabular}

Suspicious results circled; abnormal results, underlined

complete separation between the patient and normal results, even in the milder cases.

\section{Age as a confounding factor in measurements of loss of colour contrast}

In older subjects the lens scatters more and loses transparency especially at shorter wavelengths. This leads to a small increase in luminance and contrast thresholds- $0.15 \log$ unit per decade, ${ }^{52}$ or $0.19 \log$ unit/decade, ${ }^{53}$ or $0.7 \mathrm{~dB}$ per decade..$^{54}$ The relation between age and threshold has been reported as linear, ${ }^{47}$ as found in this paper. Pupillary diameter also decreases with age, and the reduction in luminance can change colour contrast thresholds. None of these changes is significant in relation to the very large changes in colour contrast sensitivity found in our subjects with ARM. In the patients, threshold may increase more rapidly with age than in the normals. The cause of this difference may simply be that the severity of ARM progresses with time.

\section{Colour contrast as a screening test for ARM}

An optotype test is familiar and quick. Untrained people can administer it. These qualities are important for screening. With smaller letters, many of our patients had thresholds higher than could be measured. Even with mild fundal changes in people newly diagnosed and previously thought to be normal, tritan thresholds may be significantly elevated. Tritan colour contrast thresholds increase greatly before the patient becomes in immediate danger of developing geographic atrophy or disciform degeneration. There is a correlation between threshold and degree of abnormality in the fundus. These results are novel and suggest it would be possible to use the system for monitoring the onset and progress of ARM. In some of the cases, repeat testing after 9 months has shown deterioration (paper in preparation), and such a deterioration with time has been reported previously. ${ }^{41}$ The usefulness of the test in practice would be to distinguish between a very large number of elderly people who have mild retinal changes, and the few with much higher and increasing thresholds who need treatment or detailed ophthalmological investigations. Criteria could be set that would distinguish such a subgroup. For example, referral from a primary screening clinic might occur when the person was unable to distinguish small tritan letters at $100 \%$ modulation, or large tritan letters at 30\% modulation (6 SD above the normal mean, see fig 3). The colour contrast test thus has potential for an improvement in patient management. Our results suggest that the referral criterion could be adjusted to suit local needs and the availability of adequate treatment and would reduce the personal and institutional costs of loss of vision. In common with all such tests it is not possible to ensure that the test will only pick up a specific pathology, but other acquired colour vision deficiencies require ophthalmological investigation.

\section{ACKNOWLEDGEMENTS}

We thank the members of the Macular Disease society for their assistance, the British Retinitis Pigmentosa Society for financial support (grant No 522), Ms J Aplin for assistance with the experimental work on filters, and $\mathrm{Mr} \mathrm{CH}$ Hogg, Mr S Perry, and Mr L Perry for technical support.

\section{Authors' affiliations}

G B Arden, J E Wolf, Applied Vision Research Centre, Department of Optometry and Visual Science, City University, London ECIV OHB, UK

Commercial interest: GBA is an unpaid scientific consultant for Breakpoint Pty.

\section{REFERENCES}

1 Lim JI, Enger C, Fine SL. Foveomacular dystrophy. Am J Ophthalmol 1994;117:1-6.

2 Treatment of Age Related Macular Degeneration with Photodynamic Therapy (TAP) Study Group. Photodynamic therapy of subfoveal choroidal neovascularization in age related macular degeneration with verteporfin: one year results of randomized clinical trials -TAP report. Arch Ophthalmol 1999:117:1329-45.

3 Bressler NM. Photodynamic therapy of subfoveal choroidal neovascularization in age-related macular degeneration with verteporfin: twoyear results of two randomized clinical trials-TAP report 2. Arch Ophthalmol 2001;119:198-207.

4 Verteporfin in Photodynamic Therapy Study Group. Verteporfin therapy of subfoveal choroidal neovascularization in age-related macular degeneration: two-year results of a randomized clinical trial including lesions with occult with no classic choroidal neovascularization-Verteporfin in Photodynamic Therapy Report 2. Am J Ophthalmol 2001;131:541-60.

5 Blumenkranz MS, Bressler NM, Bressler SB, et al. Verteporfin therapy for subfoveal choroidal neovascularization in age-related macular degeneration: 
three-year results of an open-label extension of 2 randomized clinical trials TAP report no. 5. Arch Ophthalmol 2002;120:1307-14.

6 Haddad WM, Coscas G, Soubrane G. Eligibility for treatment and angiographic features at the early stage of exudative age related macular degeneration. Br J Ophthalmol 2002;86:663-9.

7 la Cour M, Kiilgaard JF, Nissen MH. Age-related macular degeneration: epidemiology and optimal treatment. Drugs Aging 2002;19:101-33.

8 Starr CE, Guyer DR, Yannuzzi LA. Age-related macular degeneration. Can we stem this worldwide public health crisis? Postgrad Med 1998;103:153-64.

9 Lanchoney DM, Maguire MG, Fine SL. A model of the incidence and consequences of choroidal neovascularisation secondary to age-related macular degeneration. Comparative effects of currrent treatment and potential prophylaxis on visual outcomes in high-risk patients. Arch Ophthalmol 1998; 116:1045-52.

10 Sickenberg $M$. Early detection, diagnosis and management of choroidal neovascularisation in age-related macular degeneration. The role of ophthalmologists. Ophthalmologica $2001 ; 215: 247-53$.

11 Oneill C, Jamison J, McCulloch D, et al. Age-related macular degeneration: cost-of-illness issues. Drugs Aging 2001;18:233-41.

12 La Heij EC, Liem AT, Hendrikse F. Age-related macular degenration; therapeutic options. Ned Tijdsch Geneeskd 2001;145:1390-7.

13 Marcus M, Merin S, Wolf M, et al. Electrophysiologic tests in assessment of senile macular degeneration. Ann Ophthalmol 1983;15:235-8.

14 Sunness JS, Massof RW. Focal electro-oculogram in age-related macular degeneration. Am J Optom Physiol Opt 1986;63:7-11.

15 Rover J, Bach M. C-wave versus electrooculogram in diseases of the retinal pigment epithelium. Doc Ophthalmol 1987;65:385-9.

16 Gupta LY, Marmor MF. Sequential recording of photic and non-photic electrooculogram responses in patients with extensive extramacular drusen. Doc Ophthalmol 1994;88:49-55.

17 Lim Jl, Enger C, Fine SL. Foveomacular dystrophy. Am J Ophthalmol 1994;117:1-6.

18 Holopigian K, Seiple W, Greenstein V, et al. Relative effects of ageing and age-related macular degeneration on peripheral retinal function. Optom Vis Sci 1997;74:152-9

19 Shirao Y, Ushimura S, Kawasaki K. Differentiation of neovascular maculopathies by non-photic electrooculogram responses. Jpn J Ophthalmol 1997:41:174-9.

20 Falsini B, Serrao S, Fader A, et al. Focal electroretinograms and fundus appearance in non-exudative macular degeneration. Quantitative relationship between retinal morphology and function. Graefes Arch Clin Exp Ophthalmol 1999;237:193-200.

21 Walter P, Widder RA, Luke C, et al. Electrophysiological abnormalities in age related macular degeneration. Graefes Arch Clin Exp Ophthalmol 1999;237:962-8.

22 Huang $S$, Wu D, Jaing $F$, et al. Multifocal electroretinogram in age-related maculopathies. Doc Ophthalmol 2000;101:115-24.

23 Li J, Tso MO, Lam TT. Reduced amplitude and delayed latency in foveal response of multifocal electroretinogram in early age- related macular degeneration. Br J Ophthalmol 2001;85:287-90

24 Brown B, Adams AJ, Coletta NJ, et al. Dark adaptation in age-related maculopathy. Ophthalmic Physiol Opt 1986;6:81-4.

25 Eisner A Stombos VD, Klein ML, et al. Relations between fundus appearance and function. Eyes whose fellow eye has exudative age-related macular degeneration. Invest Ophthalmol Vis sci 1991;32:8-20.

26 Owsley C, Jackson GR, Cideciyan AV, et al. Psychophysical evidence for rod vunerability in age-related macular degeneration. Invest Ophthalmol Vis Sci 2000;41:367-73.

27 Cheng AS, Vingrys AJ. Visual losses in early age-related maculopathy. Optom Vis Sci 1993;70:79-96.

28 Medina E, Degli Angeli C, Barzino MC, et al. Macula function impairment in eyes with early age-related macular degeneration. Invest Ophthalmol Vis Sci 1997; 38:469-77.

29 Dorris N, Hart PM, Chakravathy U, et al. Relation between macular morphology and visual function in patients with choroidal neovascularisation of age related macular degeneration. Br J Ophthalmol 2001;85:184-8.
30 Remky A, Lichtenberg $\mathrm{K}$, Elsner AE, et al. Short wavelength automated perimetry in age related maculopathy. Br J Ophthalmol 2001;85:1432-6.

31 Smith VC, Pokorny J, Diddy KR. Color matching and the Stiles-Crawford effect in observers with early age-related macular changes. J Opt Soc Am A 1988:5:2113-21.

32 Arden GB, Gunduz K, Perry S. Colour vision testing with a computer graphics system. Clin Vis Sci 1988;2:303-20.

33 Gunduz K, Arden GB, Perry S, et al. Colour vision defects in ocular hypertension and glaucoma: quantification with a computer driven colour television system. Arch Ophthalmol 1988;106:929-36.

34 Arden GB, Gunduz K, Perry S. Color vision testing with a computer graphics system: preliminary results. Doc Ophthalmol 1988;69:167-74.

35 Gunduz K, Arden GB. Changes in colour contrast sensitivity associated with operating argon lasers. Br J Ophthalmol 1989;73:241-6.

36 Tak Yu V, Falcao-Reis F, Spileers W, et al. Peripheral colour contrast. A new screening test for preglaucomatous visual loss. Invest Ophthalmol Vis Sci 1991;32:2779-89.

37 Arden GB, Berninger T, Hogg CR, et al. A survey of colour discrimination in German ophthalmologists. Ophthalmology 1991;5:567-75.

38 Ulbig MRW, Arden GB, Hamilton AMP. Colour contrast sensitivity and pattern electroretinographic findings after diode and argon laser photocoagulation in diabetic retinopathy. Am J Ophthalmol 1994;117:583-588.

39 Arden GB, Hall M. Does occupational exposure to argon laser radiation decrease colour contrast sensitivity in UK ophthalmologists? Eye 1995:9:686-96.

40 Knoblauch K, Vital-Durrand F, Barbur JL. Variation of chromatic sensitivity across the life span. Vis Res 2001;41:23-36

41 Holtz FG, Gross-Jendrowska M, Eckstein A, et al. Colour contrast sensitivity in patients with age-related Bruch's membrane changes. Ger J Ophthalmol 1985;4:336-41.

42 Frennesson JC, Nilsson UL, Nilsson SE. Colour contrast sensitiviity in patients with soft drusen, and early stage of ARM. Doc Ophthalmol 1995:90:377-86

43 Frennesson JC, Nilsson SE. Laser photocoagulation of soft drusen in early age-related maculopathy (ARM). The one-year result of a prospective randomised trial. Eur J Ophthalmol 1996:3:307-14.

44 Frennesson JC, Nilsson SE. Prophylactic laser treatment in early age related maculopthy reduced the incidence of exudative complications. Br J Ophthalmol 1998;82:1169-74.

45 Wyszecki G. Stiles WS. Color science: concepts and methods, quantitative data and formulae, 2nd ed. USA: John Wiley, 1982; Chapter 5, 306-8.

46 Weale RA. Age and the transmittance of the human crystalline lens. J Physiol Lond 1988:395:577-87.

47 Nguyen-Tri D, Overbury O, Faubert J. The role of lenticular senescence in age-related colour vision changes. Invest Ophthalmol Vis Sci 2004; (in press).

48 Arden GB, Wolf JE. The Human electro-oculogram: interaction of light and alcohol. Invest Ophthalmol Vis Sci 2000;41:2722-9.

49 Arden GB, Wolf JE. Differential effects of light and alcohol on the electrooculographic responses of patients with age-related macular disease. Invest Ophthalmol Vis Sci 2003;44:3226-32.

50 Bird AC, Bressler NM, Bressler, et al. An international classification and grading system for age-related maculopathy and age-related macular degeneration. Surv Ophthalmol 1995;39:367-74.

51 Eisner A, Fleming SA, Klein ML, et al. Sensitivities in older eyes with good acuity: eyes whose fellow eye has exudative AMD. Invest Ophthalmol Vis Sci 1987:28:1832-7.

52 Johnson CA, Adams AJ, Twelker JD, et al. Age -related changes in the central visual field for short-wavelength sensitive pathways. J Opt Soc Am A 1988;5:2131-9.

53 Remki A, Elsner AE, Morandi AJ, et al. Blue-on-yellow perimetry with a scanning laser ophthalmoscope: small alterations in the central macula with aging. J Opt Soc Am A Opt Image Sci Vis 2001;18:1425-36

54 Adams CW, Bullimore MA, Wall $M$, et al. Normal ageing effects of frequency doubling technology perimetry. Optom Vis Sci 1999;76:582-7. 